\title{
Single Layer Dual band Microstrip Patch Antenna using Probe Feed
}

\author{
Tej Raj \\ M Tech Scholar \\ DIT Dehradun India
}

\author{
Brajlata Chauhan \\ Astt. Professor \\ DIT Dehradun India
}

\begin{abstract}
Previously it was shown that multiple bands Microstrip patch antenna can be designed using aperture coupled stacked configuration, L-probe fed patches, M-probe fed patches, and coax fed stacked patches. In all above techniques it creates complexity to design and complicated feed or more than one patch. In this paper broadband patch antenna using single uslot is simulated and broadband operation is achieved and then additional u-shaped slots is introduced to create the additional notch frequency which turn into multiple band patch antenna. Advantage of such configuration that the complexity is reduced, simple feed and single patch is used. Simulation results are presented to demonstrate the practicability of this design.
\end{abstract}

\section{Keywords}

MSA-Microstrip Antenna

\section{INTRODUCTION}

Mictrostrip patch antenna becomes most attractive antenna design today because of many commercial applications such as cellular mobile communication and satellite communication etc. But MSA suffers from many of drawback like low impedance bandwidth, low gain. Many of literature are available for enhancing the impedance bandwidth of antenna. Single layer and single patch antenna is designed using u-shaped slot cut to obtain the broadband operation [1][3].

In some of applications it is needed to design the MSA which cover the two or more frequency bands for which closer to each other [4].Stacked patches design having two or more bands can be extended. From [5] multiband antenna is designed with small frequency ratio with 1.11 to 1.18 .Form [3] Stacked patch configuration of five bands is demonstrated with a frequency ratio of successive bands are 1.113, 1.195, 1.280 and 1.4.A new techniques to designing the dual and triple band is proposed in [3]-[5].First with a single u-slot is cut in the patch leads to broadband operation is achieved and then additional $u$ slot of proper dimensions is cut into the patch which generates additional band notch at a frequency in the original broadband. Thus dual band antenna is become from the broadband.

For broadband operation design first, antenna having a single $\mathrm{u}$ - slot is come up which provides the broadband characteristics. Using existing literature [3]-[8] slot provides the band notch of the half wavelength long slot and width of slot is approximately $0.16 \lambda$ to $0.01 \lambda$. [6,7]. The location of $\mathrm{u}$-slot is chosen best to provide the impedance match using simulation software Ansys HFSS.

Fig. 1(a) shows the geometry of broadband u-slot patch antenna. The dimensions of antenna are given in the table 1 .
The antenna impedance bandwidth, Gain and VSWR shown in fig. 1, fig 2 and fig. 3 respectively. The impedance bandwidth of antenna about $30 \%$ is achieved.

Another u-slot is cut in the patch of half wavelength long to introduce the new band notch in the broadband antenna shown in fig. 1(b). Dimensions of antenna are given in table 1. The antenna impedance bandwidth and VSWR are shown in fig. 4 and fig. 5 respectively. Now antenna is dual band with resonant frequency $3.622 \mathrm{GHz}$ and $4.684 \mathrm{GHz}$ with $9 \%$ and $12 \%$ impedance bandwidth is achieved respectively.

\section{Antenna Design and simulations 2.1 Design1: Antenna design with single u- slot}

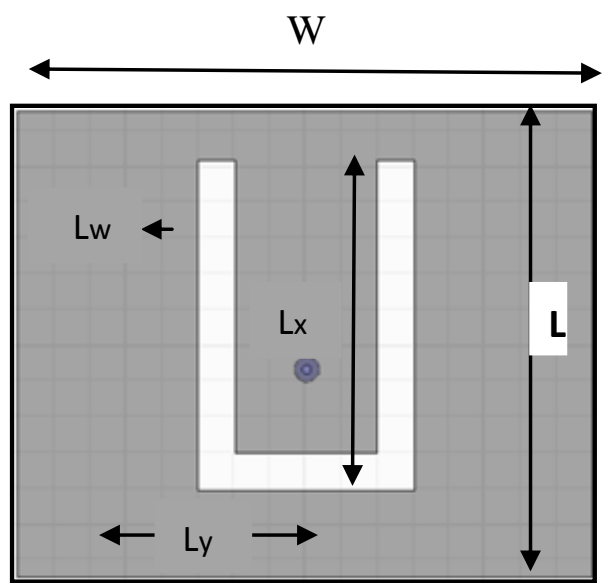

Fig. 1(a) Single u-slot patch with probe feed.

Single u-slot patch antenna is shown in figure 1(a) with the slot length approximately half wavelength long. Because it provides better results [9].MSA is fed with coaxial probe feed with diameter $0.7 \mathrm{~mm}$. Thickness of substrate is taken to be 6 $\mathrm{mm}$ which is approximately $0.08 \lambda_{0}$. Slot dimensions are optimized to $\mathrm{Lx}=18.5 \mathrm{~mm}$ (length along $\mathrm{x}$-axis) and $\mathrm{Ly}=8 \mathrm{~mm}$ (length along y-axis).

\subsubsection{Results and Discussions}

After optimization of slot dimensions, the total slot length is $45 \mathrm{~mm}(2 \mathrm{Lx}+\mathrm{Ly})$ which is approximately to the half wavelength long of resonant frequency [9]. The impedance bandwidth of $30.12 \%$ is achieved. Dimensions of patch are shown in table 1 . The performance table for various feed position, return loss and impedance bandwidth is shown in table 2.S parameter, Gain and VSWR is shown in fig.1, 2 \& 3 respectively. 
Table 1: Dimensions of single u-slot patch antenna

\begin{tabular}{|c|c|c|c|c|c|}
\hline Antenna & W & L & Lx & Ly & Lw \\
\hline $1(a)$ & 32 & 26 & 18.5 & 12 & 2 \\
\hline
\end{tabular}

All dimensions are in $\mathrm{mm}$.

Table2: Performance of single u-slot patch antenna

\begin{tabular}{|c|c|c|c|c|}
\hline Case & $\begin{array}{c}\text { Feed position } \\
\mathrm{mm}\end{array}$ & $\begin{array}{c}\text { Resonant Frequency } \\
\mathrm{GHZ}\end{array}$ & RL Loss(dB) & $\begin{array}{c}\text { Impedance Bandwidth } \\
\mathrm{GHz}\end{array}$ \\
\hline 1 & $(0.5,0.1)$ & 4.22 & -11.93 & $3.66-4.78(26.51 \%)$ \\
\hline 2 & $(0.8,0.1)$ & 4.25 & -11.40 & $3.66-4.83(27.61 \%)$ \\
\hline 4 & $(1.1,0.1)$ & 4.29 & -11.22 & $3.66-4.91(29.07 \%)$ \\
\hline 5 & $(1.4,0.1)$ & 4.30 & -11.09 & $3.65-4.99(30.15 \%)$ \\
\hline
\end{tabular}

From the performance table of single u-slot patch is optimized for various feed position. Corresponding feed position return loss and impedance bandwidth range is shown. From sparameter curve in figure 1 the impedance bandwidth of antenna is shown for different feed position. Figure 2 shows the VSWR which is less than two for entire bandwidth from $3.66-4.78 \mathrm{GHz}$. Figure 3 shows the gain of antenna at center frequency $4.3 \mathrm{GHz}$ with maximum gain is $8.87 \mathrm{~dB}$.

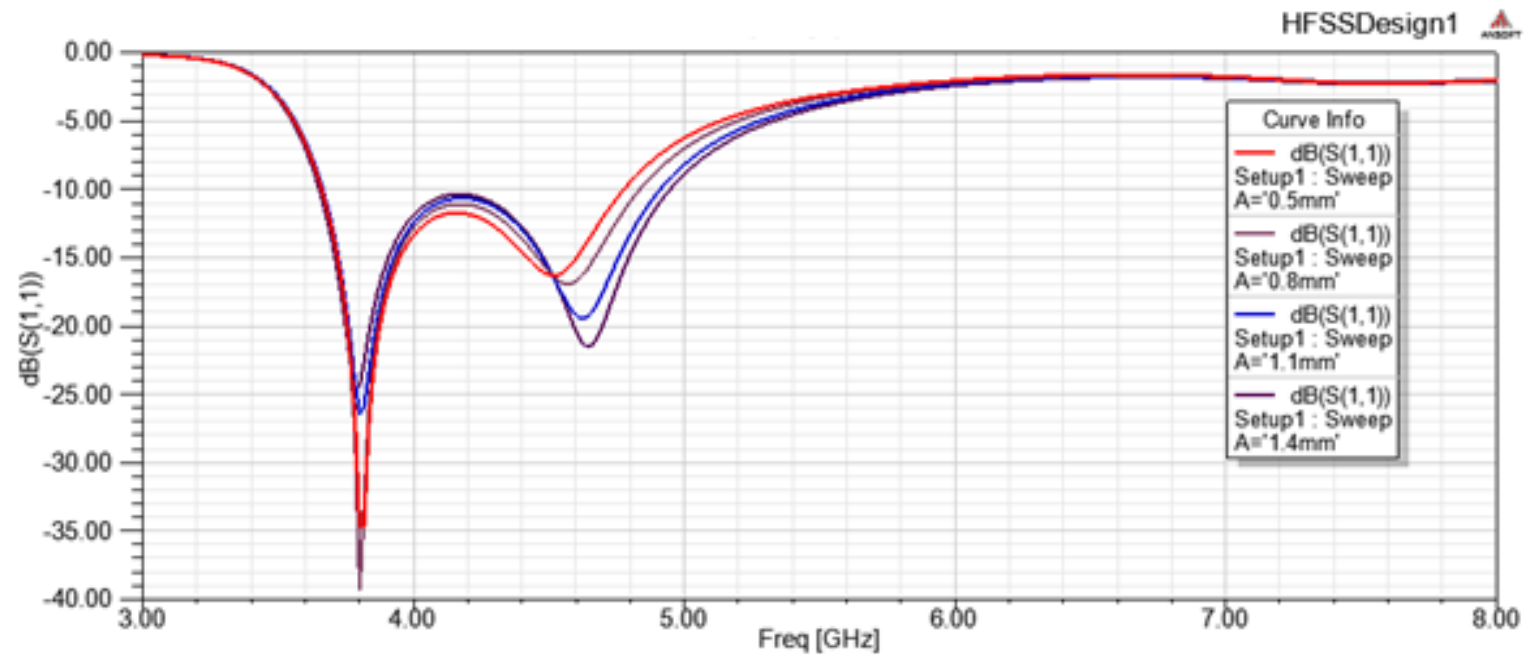

Figure1: S parameter curve

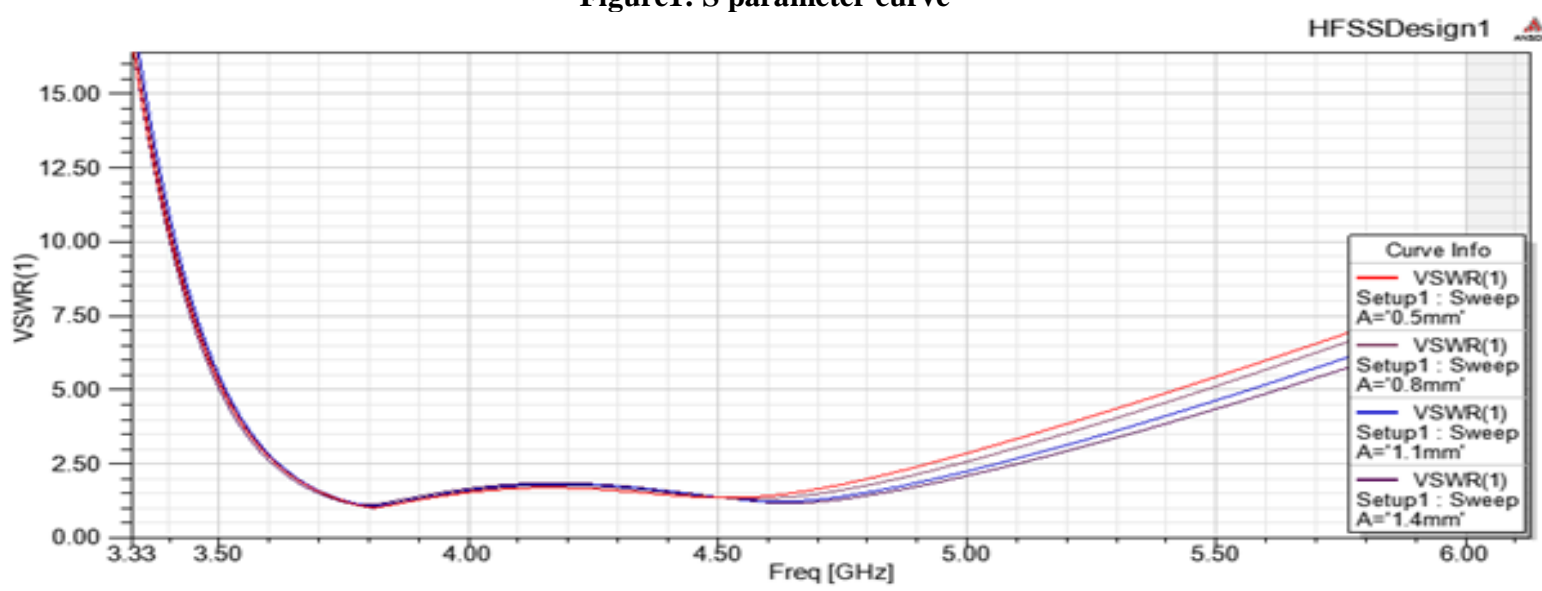

Figure 2: VSWR curve $<2$ 


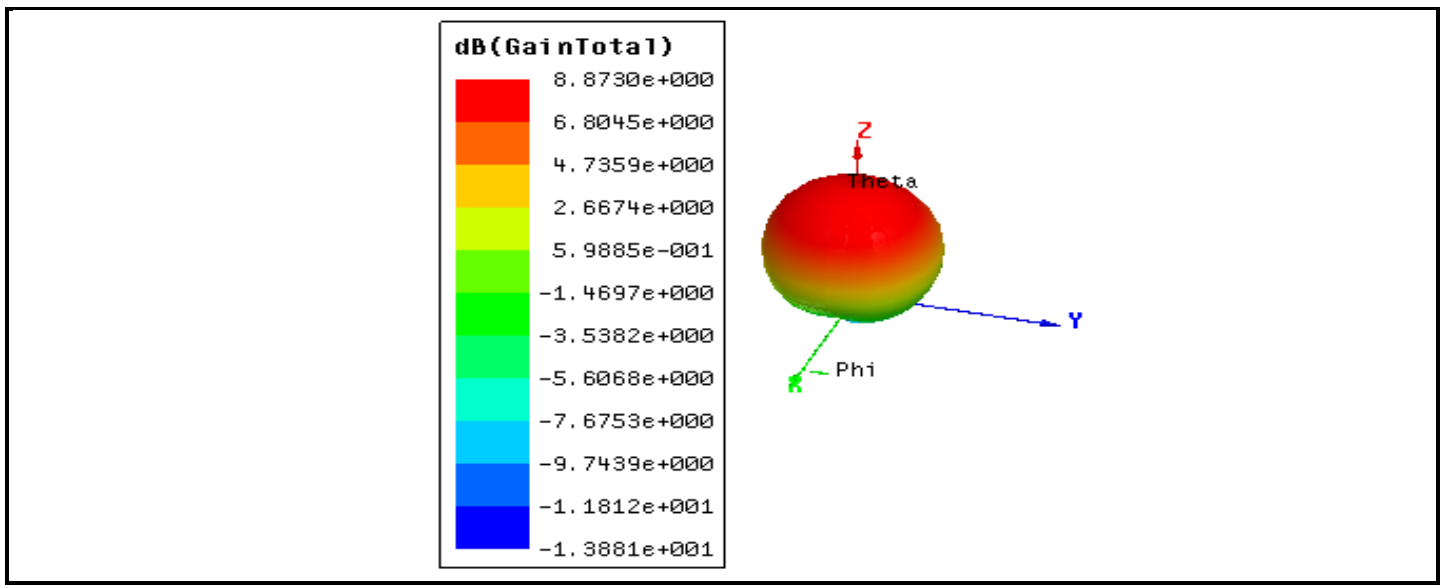

Figure 3: Polar plot of Gain of antenna at resonant frequency $4.3 \mathrm{GHz}$

\subsection{Design 2: Antenna design with double u- slot}

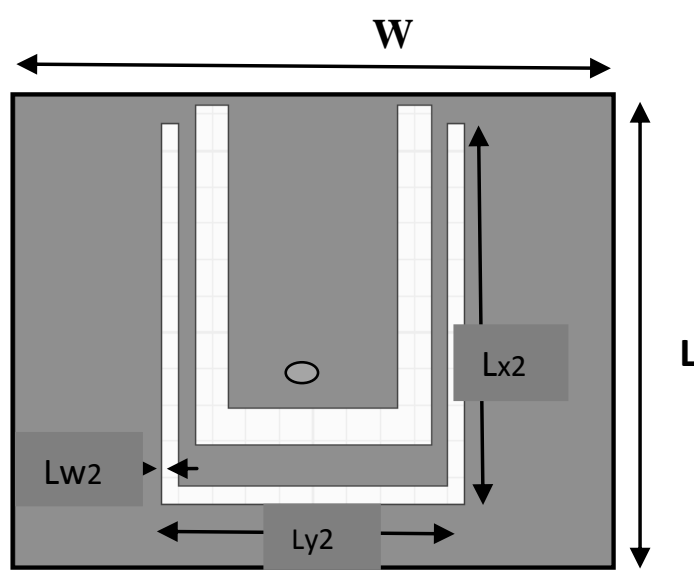

Fig. 1(b) Double u-slot patch antenna

In design 2 another $\mathrm{u}$-slot is cut in the patch and results in dual band Microstrip antenna. Slot Dimensions are optimized to get proper results. Thickness of the substrate is same as in case of single u-slot. Slot dimensions are optimized to $\mathrm{Lx}=21$ $\mathrm{mm}$ (Length along $\mathrm{x}$-axis) and $\mathrm{Ly}=18 \mathrm{~mm}$ (length along $\mathrm{y}$ axis).Second slot is optimized from the bottom edge of patch for every $0.2 \mathrm{~mm}$ for optimum results and feed positions is varied to provide best impedance matching.

\subsubsection{Results and Discussions}

After optimization of second slot, total length is $60 \mathrm{~mm}(2 \mathrm{Lx}+$ Ly). Antenna is now dual band with resonant frequency 3.622 $\mathrm{GHz}$ and $4.6847 \mathrm{GHz}$ respectively. The bandwidth is achieved $9 \%$ and $12.6 \%$ respectively. S parameter, gain and VSWR are analyzed.

Table 3: Dimensions of double u-slot patch antenna

\begin{tabular}{|l|l|l|l|l|l|}
\hline Antenna & $\mathbf{W}$ & $\mathbf{L}$ & $\mathbf{L}_{\mathbf{x}}$ & $\mathbf{L}_{\mathbf{y}}$ & $\mathbf{L}_{\mathbf{w} \mathbf{2}}$ \\
\hline $1(\mathrm{~b})$ & 32 & 26 & 19 & 16 & 1 \\
\hline
\end{tabular}

All dimensions are in $\mathrm{mm}$

\begin{tabular}{|c|c|c|c|c|}
\hline Case & $\begin{array}{c}\text { Feed position } \\
(\mathbf{m m})\end{array}$ & $\begin{array}{c}\text { Resonant Frequency } \\
(\mathbf{G H z})\end{array}$ & RL Loss (dB) & Impedance Bandwidth \\
\hline $\mathbf{1}$ & $(0.5,0)$ & $3.6,4.6$ & -14.17, & $3.49-3.80(8.47 \%)$, \\
& & & -13.91 & $4.35-4.85(11.05 \%)$ \\
\hline $\mathbf{2}$ & $(1,0)$ & $3.62,4.63$ & -15.60, & $3.44-3.80(10 \%)$, \\
& & & -15.32 & $4.35-4.85(12.13 \%)$ \\
\hline $\mathbf{4}$ & $(1.5,0)$ & $3.64,4.68$ & -18.91, & $3.47-3.81(9.44 \%)$, \\
& & & -18.50 & $4.37-5.02(13.29 \%)$ \\
\hline $\mathbf{5}$ & $(2,0)$ & $3.58,4.65$ & -17.67, & $3.42-3.73(8.59 \%)$, \\
& & & -16.60 & $4.35-4.96(13.37 \%)$ \\
\hline
\end{tabular}

From the performance table of double u-slot resonant frequencies and corresponding return loss is analyzed for various feed positions. From s-parameter curve in figure 4 the impedance bandwidth of antenna is shown for different feed position as shown. Figure 5 shows the VSWR which is less than two for both frequency bands which has center frequency $3.64 \mathrm{GHz}$ and $4.68 \mathrm{GHz}$. Figure 6 and 7 shows the gain of antenna at center frequency $3.64 \mathrm{GHz}$ and $4.68 \mathrm{GHz}$ respectively. 


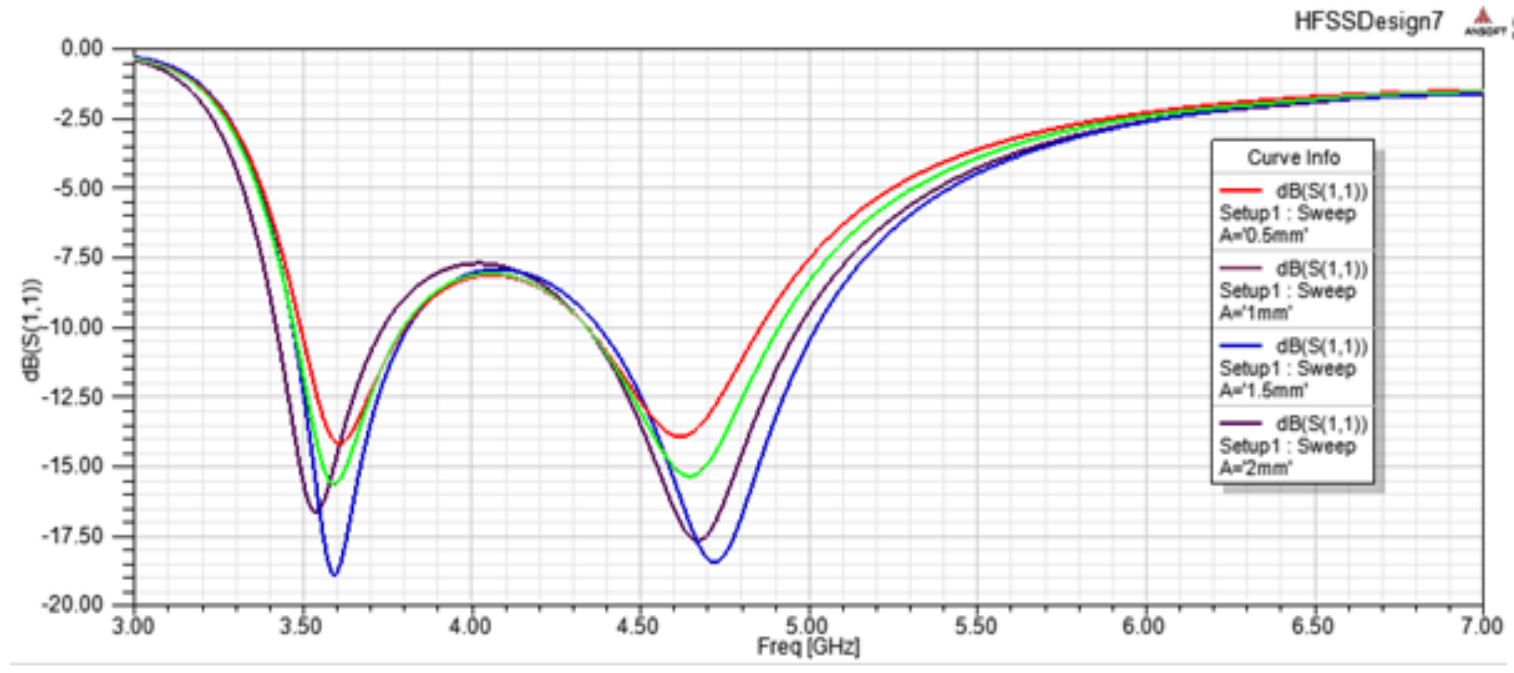

Figure 4: S parameter curves for different feed position.

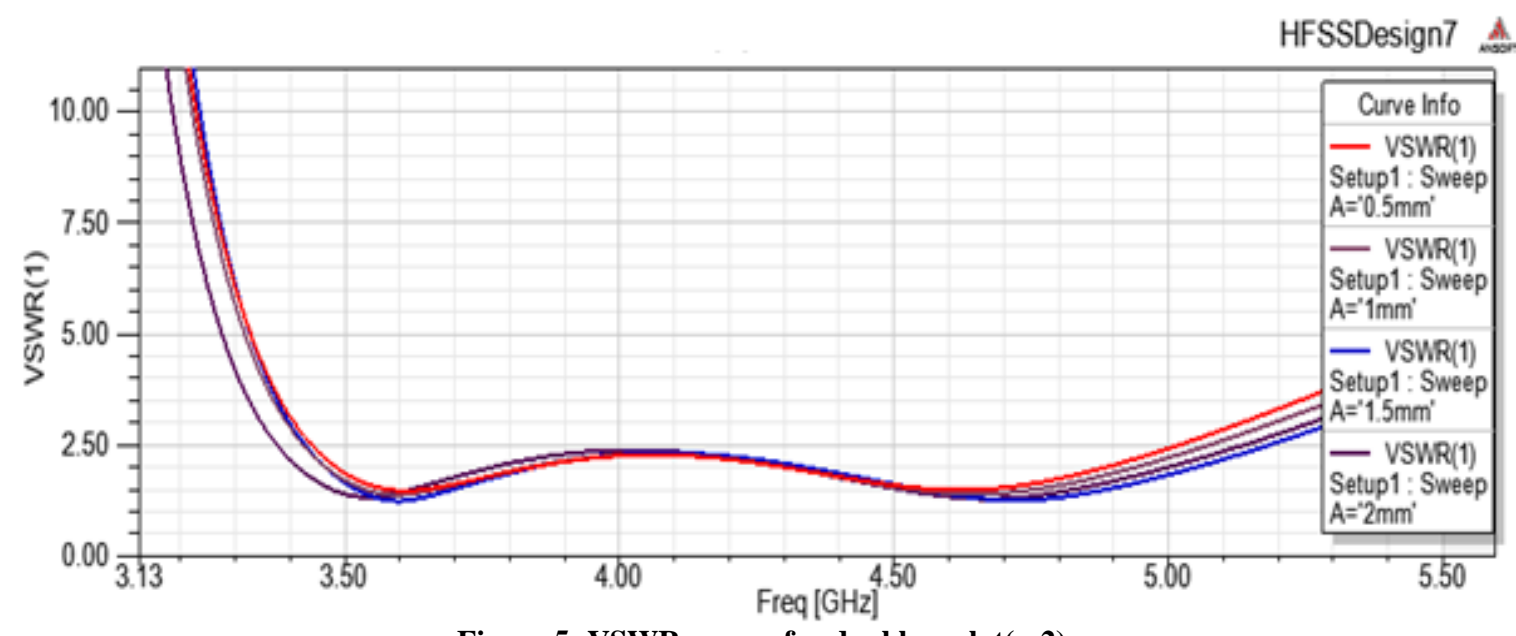

Figure 5: VSWR curves for $\operatorname{double} u-\operatorname{slot}(<2)$

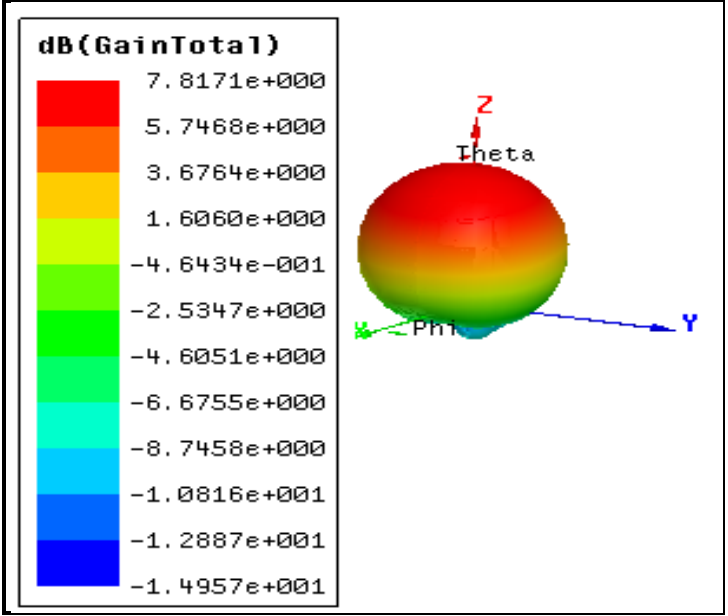

Figure 6: Polar plot of a patch antenna, at $3.64 \mathrm{GHz}$ $(1.5 \mathrm{~mm}, 0 \mathrm{~mm})$ resonant frequency

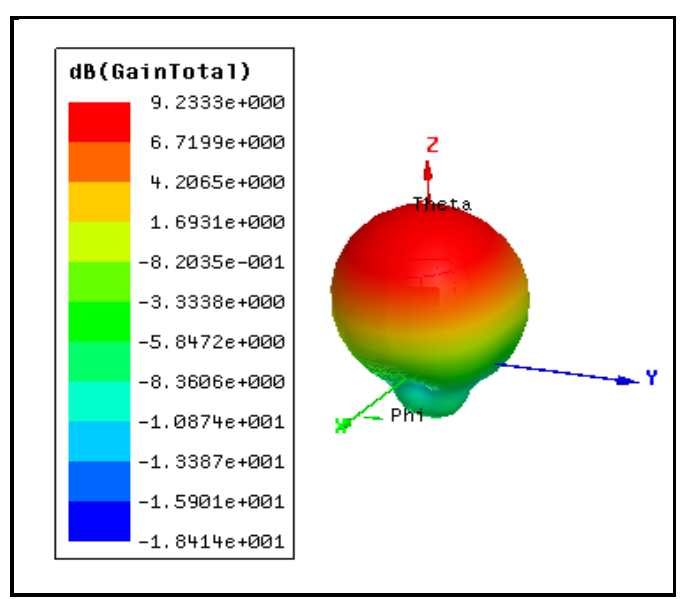

Figure 7: Polar plot of a patch antenna, at $4.68 \mathrm{GHz}$ $(1.5 \mathrm{~mm}, 0 \mathrm{~mm})$ resonant frequency 


\section{CONCLUSION}

In this paper a dual band antenna has implemented and analyzed using Ansys HFSS. Single u-slot has provided the impedance bandwidth of $30 \%$ with gain of antenna $8.7 \mathrm{~dB}$. Another u-slot cut into the patch which results in dual band operation. Advantage of this configuration is simple structure and single patch is used as given in [4].

\section{REFERENCES}

[1] Kin-Fai Tong, Kwai-Man Luk, Senior Member, IEEE, Kai-Fong Lee, Fellow, IEEE, and Richard Q. Lee "A Broad-Band U-Slot Rectangular Patch Antenna on a Microwave Substrate." IEEE transactions on antennas and propagation, vol. 48, no. 6, June 2000.

[2] K. F. Lee, K. M. Luk, K. F. Tong, S. M. Shum, T. Huynh, and R. Q. Lee, "Experimental and simulation studies of coaxially fed U-slot rectangular patch antenna," Inst. Elect. Eng. Proc. Microwave Antennas Propagat. vol. 144, no. 5, Oct. 1997.

[3] S. Weigand, G. H. Huff, K. H. Pan, and J. T. Bernhard, "Analysis anddesign of broad-band single-layer rectangular U-slot microstrip patch antenna," IEEE Trans. Antennas Propag., vol. 51, no. 3, pp. 457-468, 2003.
[4] Wing Chi Mok, Sai Hoi Wong, Kwai Man Luk, and Kai Fong Lee " Single-Layer Single-Patch Dual-Band and Triple-Band Patch Antennas "IEEE transactions on antennas and propagation, vol. 61, no. 8, august 2013.

[5] S. A. Long and W. D. Walton, "A dual-frequency stacked microstrip circular-disc antenna," IEEE Trans. Antennas Propag., vol. AP 27, no.3, pp. 270-273, 1979.

[6] Ban-leong Ooi, shen qin and mook-seng leong. "a novel design of broad- band stacked patch antenna "IEEE transactions on antennas and propagation, vol. 50, no. 10, October 2002.

[7] Compact and broadband microstrip antenna,kin-Lu Wong Copyright 2002 John Wiley and sons.

[8] Fan Yang, Xue-Xia Zhang, Xiaoning Ye, Yaha Rahmat Samii "Wide band E- shaped patch antennas for wireless communications" IEEE transactions on antennas and propagation, vol. 49, no. 7, July 2001.

[9] Sanjeev Kumar Sharma and Munish Rattan "Analysis of Broad Banding and Minimization Techniques for Square Patch Antenna" journal of IETE research vol 56 issue 2 mar-apr 